\title{
The Impact of Multimodal Discourse on Iraqi EFL Learners' Writing Skills
}

\author{
Mohammad Kiani Harchegani , and Kawa Abdlkareem Sherwani ${ }^{\text {b }}$ \\ A \\ Salahadin University, College of Languages, Department of English, \\ Knowledge University, College of Arts, Department of English Language. \\ B Media Techniques Department, Erbil Technical Administrative College, Erbil \\ Polytechnic University, Kurdistan region of Iraq
}

Article History: Received: 11 January 2021; Accepted: 27 February 2021; Published online: 5 April 2021

\begin{abstract}
The present study was conducted to investigate the impact of multimodal discourse on Iraqi EFL learners' writing skills. To achieve the goal, a group including 40 Iraqi EFL learners participated in the free paragraph writing course based on their scores in a Placement Test. Selected participants were randomly assigned to control $(\mathrm{N}=20)$ and experimental $(\mathrm{N}=20)$ groups. Prior to the start of the course, both groups were given the pretest (writing test). The experimental group was exposed to the treatment (multimodal use of discourse, e.g. video and picture based on Halliday's social semiotics approach) and the control one did not receive any treatment. Having accomplished the experiment, participants of the two groups completed two writing tasks as the posttest. Results of t-test indicate significant outperformance of the experimental group over the control one.
\end{abstract}

Keywords: Multimodal Discourse, EFL Learners, Writing Skills, Experimental study

\section{Introduction}

In the language teaching, one of the main standards to measure the teaching effect is the sufficient and effective communication between teachers and learners to achieve the communicative purpose. Multimodal discourse is not limited to the written text but extended to other forms of expressions such as sounds, pictures, colors, and cartoons while discourse analysis proposed by Harris analyzes the internal consistencies of discourse activities, and the relationships between them and mental modes., while (Harris, 1952, quoted in Zhu, 2007), which has become the application of researches both within and outside Iraq. Consequently, observing the need to fill the research gap concerning the role of multimodal discourse in Iraqi EFL learners' writing skills in the context of Iraq, this study aimed to investigating whether multimodal discourse had any significant impacts on improving Iraqi EFL learners' writing skills. This study also aimed at investigating whether there was a significant difference in using multimodal discourse for male and female Iraqi EFL learners'.

This study attempts to answer the following questions:

1- Does multimodal discourse have any significant impact on EFL learners' writing skill?

2- Can multimodal discourse-based teaching improve Iraqi EFL learners' writing skills?

\section{Review of Literature}

\subsubsection{Multimodal discourse and multimedia}

We are living in the 21 st century in which discourse can have grate impacts on different aspects our life, for example, on education language learning, language teaching, etc. Also, discourse and here multimodal discourse can affect the linguistic ability of language learners, such as, their writing skills etc. Halliday (1985) believed that in the particular social context, people always made the most out of semiotic resources to achieve the design of meaning and accordingly different semiotic resources constituted multimodality (quoted in Kress \& van Leeuwen, 2001, p. 80). Nowadays, the multimodal discourse theory becomes gradually necessary in the language teaching. LeVine \& Scollon (2004) deemed that multimodal was related to the different modals which were used in communication, including films, videos, speech, pictures, color, and taste. (p. 3-5).

Other scholars suggested that multimodal discourse pertained to the interaction via more than two organs (Hu, 2007; Gu, 2007; Zhang, 2009; Zhu, 2008).

Modal and media are the two main terms in the realm of multimodal discourse. The former is the medium through which information communication is obtained among people, or the transmitter of information, and the medium which includes more than two transmitters is called multimedia (Gu, 2007). Hence, multimedia is closely connected to with multimodal. On the one hand, the development of multimedia technology has promoted the existence of new type of discourse. On the other hand, multimodal discourse has to refer to multimedia means for help, e.g. the transcription and sound, the interception and decomposition of dynamic image pictures, and the creation of corpus, etc. Accordingly, the development of multimodal discourse will promote the combination of multimodal and multimedia (Xin, 2008). Therefore, writing skills model via multimodal in EFL teaching has to be supported by the multimedia technology and equipment.

\subsubsection{Multimodal discourse and Multiliteracies}


In the 2000s, the new London Group including eleven linguists firstly suggested the concept of multiliteracy. They believed that with the quick progress of information technology, people had to have contact with various information of medium transmission on a daily basis, such as print, films, pictures, videotapes and communicate with culture groups with different backgrounds. Therefore, it is vitally necessary to develop learners' multiliteracies in EFL teaching.

Multiliteracy includes five elements: (1) linguistic components, e.g. vocabulary, metaphor, structure and mood; (2). auditory components, e.g. voice, music and video effects, etc. (3) visual components, e.g. color, perspective, vector, prospect, and background, etc. (4) space components, e.g. ecological space, geometry space and building space, etc. (5) posture components, e.g. behavior, feeling, physical control, emotion and movement, etc.(Gentle, Knight \& Corrigan, quoted in Zhu, 2008).

It proves to be one of the effective methods to introduce multimodal teaching, connect multiliteracy with modal and media transition to develop learners' multiliteracies, achieve the interaction between the fives sense organs, so that, learners will better adapt themselves to the multi-lives in the future (Wei, 2009). Helgesen (2003), Rost (2002) and Richards \& Schmidt (2002) all defined writing as an active process of meaning creation. In other words, the writer does not simply decode what he has written, but also actively obtains information from what he has written and connects it with his known knowledge (Rubin, 1995). Accordingly, writing teaching is the first phase of multimodal teaching and also the key stage via which multiliteracy competence is achieved.

Scholars made some valuable suggestions for it. Kress et al. (2001, p. 42) suggested that in the EFL classroom the conduct, visual and linguistic semiotic resources introduced by teachers and learners ought to be made full use of and the interaction between the resources should be promoted in order to achieve the creation and literacy of complete meanings. Healy suggested four stages for classroom teaching, namely situated practice, critical framing and transforming practice, overt instruction, (quoted in $\mathrm{Hu}, 2007$ ). Led by teachers, learners might experience, analyze and use the multimodal texts, and become subjects of the classroom teaching to develop their overall EFL learners (Abdulkareem, 2020).

The fact is that according to the traditional writing skills, learners achieve information via auditory sense or single modal, without modal transition from auditory intelligence to writing. Hence, it means a modal transition to lead oral introduction about background before writing, videos during writing and oral repetition or classroom discussion after writing. In other words, the auditory modal of input is changed into measure and writing modal of visual nerve, body movement and vocal organ (Zhang, 2009). The change of modal might strengthens the internalization of the familiarity that learners have learned, and transform more input into in-take (Long \& Zhao, 2009).

\subsubsection{Writing skills}

As Knoblauch and Brannon (1984) point out, good writing is independent of linguistic conventions. There is no plan for writing. In other words, writing skill is not a skill to be skilled, but it is result of a explicit and conscious intelligence. According to Zimmerman and Reisemberg (1997), writing has been described as simplistic and linear, task based on early models of it. Today however, researchers know how to cope with the rules, and techniques of writing such as organization, framework, form and characteristics, purposes, audience perspectives, needs of audience, etc. (Bereiter \& Scardamalia, 1987; Haris \& Graham, 1992, 1996). Individuals do not write to cover procedures or models of writing; they write since they want to connect important thought and to make meaning. Teachers should not only create motivation and contexts for thinking, but also they should encourage learners to systematize their knowledge by means of language. Allami and Salmani-Nodoushan (2007, p. 67) mentioned that writers should try to make revolution with their discourse to connect their desired meaning to solve the problem of interaction with their audience. This is the time when teachers should create "productive thinking" in their learners through encouraging appropriate strategies based on which the writers can get closer to their proposed meaning. They involve their learners in various tasks, and promote them to practice different procedures or techniques.

Shojaei and Fatemi (2016, P.173) mentioned that writing assessment has involved a considerable amount of attention in school, universities and colleges because they link learning, teaching, and assessment within the control and through controls in the university program.

In this research, writing skills have included a considerable amount of attention in school, universities and colleges. Within an effort to offer a more valid image of the theory of writing skills, there have been main changes in the language testing towards the development and use of tests within the past periods. In this original approach of multimodal discourse, learner writing is assessed by raters spending some kind of multimodal discourse scale which creates it different from the traditional fixed answer. This kind of multimodal discourse proffers the benefit of directly measuring candidates' creative language skills. In this concern, different models have famous features that affect the presentation (e.g. Fulcher, 2003; Kenyon, 1992).

As McNamara (2000) points out: "This method indicates the need for multimodal discourse analysis to be combined with the aims of the syllabus and to have an innovative relationship with teaching and learning." It means considering, learning, teaching and multimodal discourse as an assimilated and interdependent series of result (Lee, 2007). The procedures used within this model contain journals, checklists, logs, audiotapes, and, video, film, videotapes, discourse, and writing skills (Brown and Hudson 1998).

\section{Methodology}




\subsubsection{Participants and Setting}

The participants who answer the research questions in the present study, included 40 male and female upper intermediate EFL learners (40males and 40 females) whose age in both control and experimental groups ranged from 22 to 42, Learning English at the English department in Knowledge University and Salahaddin University in Erbil, Kurdistan Iraq, including various ethnicities from different parts of the country, took part in the study. In instruction to homogenize the participants and to make sure about their level of general proficiency, a quick placement test version 2 was administered to the participants. The measure for passing the test was scoring between 38 to 48 (equal to upper-intermediate level) based on the quick placement test version two. Then third version of Interchange/Passages Writing Placement Test Form C developed by Lesley, Hanson, and Zukowski (2005) was administered. The measure for passing the test was scoring between 5 to 7 (equal to upperintermediate level) based on the public version of IELTS Writing Band Descriptors, Task 2. Then, it was controlled among the participants who scored between 5 to 7 to see whether were also homogeneous writing skill or not. The number of the participants who took the quick placement test at Knowledge University was 40 male and female learners who were generally taking or have taken different levels of Interchanges 2, 3, or passages. Also, 40 male and female learners in Salahadin University in Erbil, Kurdistan Iraq took the quick placement test, and almost all test-takers had participated in Interchange 2, 3, or passages classes. Finally, two group of 40 male and female learners were selected as the participants of the study, one group in Knowledge University (the experimental group), and the other one in Salahadin University (the control group). All the participants of the study were Kurdish native speakers who were studying English as a foreign language and had never lived in an English speaking country.

\subsubsection{Instrumentation}

The quick placement test consisted of 60 questions with the time allocated to answer the original test was 30 minutes was given to the participants. The quick placement test questionnaire involved in two parts: Part One (Questions 1-40) for all of the students and Part Two (Questions 41-60) to determine their level of proficiency. The participants were in the same level in both control and experimental groups. The learners were asked to mark their opinions about writing questionnaire on the questionnaire within 40 minutes.

For the purposes of the present study, two instruments were used: Lesley et all's (2005) Writing Placement Test form $\mathrm{C}$ of the third edition of the Interchange/Passages Evaluation Package was applied to place all the students at the upper-intermediate level of writing skills to choose two nearly homogeneous groups and to make sure about the comparability of the experimental and the control groups. The Interchange Writing Placement Test required the learners to write a paragraph about one of the four topics offered to them within 40 minutes. The learners' writings in both experimental and control groups were related by four raters that were to be involved in the scoring of Writing Placement Test in to add valuable input to the procedure. The raters rated the learners' writing based on public (general) version of the IELTS Writing Band Descriptors, Task

After the four raters rated each written paragraph to determine the consistency of the ratings, the inter-rater reliability of the scores was estimated via calculating the average score of the raters'. The average score of the four raters' scores were compared to the IELTS Writing Band Descriptors, Task 2, in which the suitable band for upper-intermediate level was between 5 and 7.

Since this research intended to assess the writing skills of the learners, the same Writing Placement Test Form $\mathrm{C}$ of the third edition of Interchange/Passages was used not only as a test of homogeneity, but also as a pretest and as a posttest in the control and experimental groups. In fact, having taken the pretest, the learners received the post-test after a two-months-period study during which the learners in experimental received the treatment, they were given writing task with images and illustrations in them to write about, they were also asked to watch short videos about which they needed to write their prompts, whereas the control group took their normal writing classes without any images and videos being incorporated into the activities. Juxtaposing the results of the pretest and the post-test in each of the control groups and experimental, the researcher was able to understand if there was any change regarding the writing skill of the learners in each group. One important point was that based on the IELTS Writing Band Descriptors, Task 2, the students' writing scores in the pretest (that was administered both as a pretest and as a test of homogeneity) ranged from five to seven, Writing Placement Test form C of the third edition of the Interchange/Passages Evaluation Package, the learners' writing scores in the pretest (that was administered both as a pretest and as a test of homogeneity) ranged from five to seven, and the learners who got below five or above seven were crossed out of the study; Another important point was the paragraph written by the learners (in both the control and experimental groups) in the posttest were scored in the same way they were rated in the pretest.

\subsubsection{Procedures}

This study intended to examine the role of multimodal discourse in Iraqi EFL learners' writing skills. The following procedures are taken into consideration in the study process:

3.4.3. Participant selection: The researcher decided to do the research in two universities namely Knowledge and Salahadin in the city of Erbil, Kurdistan Iraq. Since the researcher was going to do the research on EFL upperintermediate learners, he wanted to make certain that all the learners were at the upper-intermediate level of writing skill, and because the syllabuses of both institutes were based on the third edition of Interchange System that was adopted from Short et al. (1997). The learners who registered in the course were required to take Lesley ET all's (2005) Writing Placement Test Form C of the third edition of the Interchange/Passages Evaluation Package. Then, among the learners who took the Interchange Writing Test in the two institutes, the researcher 
chose randomly one group of the learners as the control group (Salahadin University) and the other group of the learners (Knowledge University) as the experimental group. The students in both the control and the experimental groups participated in the writing course for two months, three sessions per week..

3.5.3. Pretest: The researcher considered the same Interchange Writing Placement Test both as test homogeneity and as one of the pretest of the study in both control and experimental groups. The learners (in both control and experimental groups) were also administrated the same Quick Placement Test for test Proficiency was scored 38 to 48. The Writing Placement Test was scored based on the public version of IELTS Writing Band Descriptors, Task two (in the "instrumentation" section, it was completely explained that how the Writing Placement Test was scored). The suitable scale for passing the Writing Placement Test was between 5 to7. Throughout the study, participants in the experimental group received the treatment, i.e. multimodal use of discourse through application of pictures, video clips and songs. Having presented multimodal discourses, the researcher provided a class discussion on the presentations. Then, participants were presented with an opportunity to write a text about the presented materials. Participants in the control group did not receive any treatment and each session the researcher instructed some points of writing an English text. For example, they were given an English text to read and write a summary. In one session, there were asked to write a descriptive text about their weekend in both classes, grammar, spelling and punctuation were checked to correct the errors.

3.6.3. Post Posttest: After two-month study, twenty four sessions, the researcher (in both the control and the experimental groups) administered two post testes (the same pretests) including Lesley et all's (2005) Writing Placement Test Form C of the third edition of Interchange / Passages Evaluation Package. Four raters scored the Writing Placement Test based on the public version of IELTS Writing Band Descriptors, Task two (the way through which the writing test was scored, was explained in the "instrumentation section"). The students' scores were below five, between 5 and 7 , and above seven.

\subsubsection{Study Design}

The participants of the study were selected from two populations in two, universities using the same educational system in Erbil, Kurdistan Iraq. The researcher placed the students of both the experimental and control group. The groups in the writing classes based on the researcher measure scores (1 to 20) and they took in the third edition of Writing Placement Test developed by Lesly et al. (2005). The instrument was administered to EFL learners at the two universities particularly based on researcher's available resources.

\subsubsection{Data procedures}

The data analyzed, completed the (25.0) version of the Statistical Package for Social Sciences (SPSS). Accordingly, Mann-Whitney Test, Wilcoxon Signed Ranks Test, Independent-Samples T-Test, and PairedSamples T-Test were estimated based on the results of One-Sample Kolmogorov-Smirnov Test that made clear the normality and non-normality of the data. Moreover, the researcher applied descriptive statistic of the data. In knowledge to analyze the data, SPSS software was used to assess descriptive and inferential statistics. A set of T-test was carried on to identify different relationships. Also an independent sample t-test was used to investigate the Gender seams.

\section{Results and discussion}

Having collected the data, using the instruments, the researcher has come up with tangible results and conclusions which are presented in the following sections.

\subsection{Results of normality}

To make sure that the data distribution is normal, One-Sample Kolmogorov-Smirnov Test was run. Table 1 shows the results.

Table 1: Results of normalizing test:

One-Sample Kolmogorov-Smirnov Test

\begin{tabular}{|c|c|c|c|c|c|c|}
\hline & & $\begin{array}{l}\text { paragr } \\
\text { aph1 }\end{array}$ & $\begin{array}{l}\text { paragr } \\
\text { aph2 }\end{array}$ & qpt & $\begin{array}{l}\text { ielts } \\
1\end{array}$ & $\begin{array}{l}\text { ielts } \\
2\end{array}$ \\
\hline $\mathrm{N}$ & & 40 & 40 & 40 & 40 & 40 \\
\hline Normal & Mean & 12.25 & 13.65 & 26. & 5.4 & 5.9 \\
\hline \multirow[t]{3}{*}{ Parameters ${ }^{\mathrm{a}, \mathrm{b}}$} & & 00 & 00 & 8500 & 125 & 500 \\
\hline & Std. Deviation & 1.72091 & 2.22515 & 2.17 & .739 & .705 \\
\hline & & & & 857 & 35 & 29 \\
\hline Extreme & Absolute & .142 & .137 & .138 & .147 & .157 \\
\hline \multirow[t]{3}{*}{ Differences } & Positive & .108 & .088 & .130 & .112 & .113 \\
\hline & Negative & -.142 & -.137 & - & - & - \\
\hline & & & & .138 & .147 & .157 \\
\hline Kolmogorov-Smirnov Z & & .900 & .870 & .874 & .930 & .995 \\
\hline Asymp. Sig. (2-tailed) & & .393 & .436 & .430 & .352 & .276 \\
\hline
\end{tabular}


As Table 1 shows data distribution is normal since Sig. (2-tailed) is greater than .05 for all variables. Nullhypothesis of the above test indicates the normality so if p-value is greater than .05 the normality is accepted.

4.2 Results of quick placement test:

Quick placement test was administered as a means to homogenize the participants. Their performance in the test was analyzed and data is shown in Table 2.

Table 2: Results of independent samples t-test for QPT

\begin{tabular}{lllllll}
\hline & $\mathrm{N}$ & $\mathrm{M}$ & $\mathrm{SD}$ & $\mathrm{Df}$ & $\mathrm{T}$ & Sig. \\
Cont. & 20 & 26.95 & 2.30 & 38 & .28 & .77 \\
Exp. & 20 & 26.75 & 2.09 & & &
\end{tabular}

As Table 2 displays, there is not any statistically significant $(\mathrm{df}=38, \mathrm{t}=.28, \mathrm{sig}=.77>.05)$ difference between the means of control $(\mathrm{N}=20, \mathrm{M}=26.95)$ and experimental $(\mathrm{N}=20, \mathrm{M}=26.75)$ in quick placement test.

4.3 Results of pretest (paragraph writing):

Means of the two groups in paragraph writing before the experiment were compared (Table 3).

Table 3: Results of independent samples t-test for pretest (paragraph writing)

$\begin{array}{lllllll}\text { Group } & \mathrm{N} & \mathrm{M} & \mathrm{SD} & \mathrm{df} & \mathrm{T} & \text { Sig. } \\ \text { Cont. } & 20 & 11.95 & 2.01 & 38 & 1.10 & .27 \\ \text { Exp. } & 20 & 12.55 & 1.35 & & & \end{array}$

Based on the data observed in Table 3, both groups are not statistically significantly $(\mathrm{df}=38, \mathrm{t}=1.10$, sig $=.27>.05$ different in paragraph writing at the start of the study. Participants' performance in IELTS pretest is also shown in Table 4.

Table 4: Results of independent samples t-test for pretest (IELTS writing)

$\begin{array}{lllllll}\text { Group } & \mathrm{N} & \mathrm{M} & \mathrm{SD} & \mathrm{df} & \mathrm{T} & \text { Sig. } \\ \text { Cont. } & 20 & 5.61 & .79 & 38 & 1.75 & .087 \\ \text { Exp. } & 20 & 5.21 & .63 & & & \end{array}$

Table 4 shows that there is not any significant difference $(\mathrm{df}=38, \mathrm{t}=1.75$, sig=.087>.05) between the two groups in IELTS writing administered at the outset of the study. Means of the control and experience groups are 5.61 and 5.21, respectively.

4.3 Results of posttest (paragraph writing):

Having implemented the treatment, the researcher tried to address the research questions of the study through comparing the means of the two groups in the writing tasks completed by the students.

Table 5: Results of independent samples t-test for posttest (paragraph writing)

$\begin{array}{lllllll}\text { Group } & \mathrm{N} & \mathrm{M} & \mathrm{SD} & \mathrm{df} & \mathrm{T} & \text { Sig. } \\ \text { Cont. } & 20 & 12.45 & 1.95 & 38 & 4.01 & .000 \\ \text { Exp. } & 20 & 14.85 & 1.81 & & & \end{array}$

According to, Table 5 participants of the experimental group $(\mathrm{M}=14.85, \mathrm{SD}=1.81)$ performed significantly $(\mathrm{df}=38, \mathrm{t}=4.01, \mathrm{sig}=.000)$ better than their counterparts in the control group $(\mathrm{M}=12.45, \mathrm{SD}=1.95)$.

To see whether there is a significant difference between the two groups in IELTS writing task, independent samples t-test was run. Table 6 shows the results.

Table 6: Results of independent samples t-test for posttest (IELTS writing)

$\begin{array}{lllllll}\text { Group } & \mathrm{N} & \mathrm{M} & \mathrm{SD} & \mathrm{df} & \mathrm{T} & \text { Sig. } \\ \text { Cont. } & 20 & 5.62 & .75 & 38 & 3.25 & .002 \\ \text { Exp. } & 20 & 6.27 & .47 & & & \end{array}$

As shown in Table 6 , there is a statistically significant $(\mathrm{df}=38, \mathrm{t}=3.25$, sig=.00) between the experimental $(\mathrm{M}=6.27 ; \mathrm{SD}=.47)$ and the control group $(\mathrm{M}=5.62 ; \mathrm{SD}=.75)$ in IELTS writing.

This research aimed at investigating the role of multimodal discourse in Iraqi EFL learners' writing skills. Writing skill shows an essential role to develop learners' contact and proficiency for the purpose of statement and communication. Considering the information that not enough study has been done to compare the role of multimodal discourse in Iraqi EFL learners' writing skills. When we incorporate teaching, learning and assessment, our assessment instrument develops a kind of knowledge instrument that is beneficiary to learners to study and improve their writing skill. The participants of the study were in the upper immediate level of proficiency so further researches should investigate other levels of ability in respect to the application of multimodal discourse in writing classrooms. This study sheds light on the way that multimodal discourse, in writing, supports learners English Essay Writing, mainly in the EFL upper intermediate context. If multimodal discourse implemented in upper intermediate, and advanced level, learners will gain knowledge in English Essay Writing. In order to investigate the role of multimodal discourse in Iraqi EFL learners' writing skill of the participants through the performance of the control and experimental groups, the participants were required to 
take the same test twice as the pre-test and post-test of the study. The present findings support the argument of Moreno and Mayer (2007) who believe that different modes are used in multimodal learning environment to represent content knowledge. In addition, Shah and Freedmen (2003, as cited in Anggrainy, 2016) argue that multimodal courses allow instructional events or elements to be presented in more than one sensory mode (multiple representations), thus further facilitating student's learning.

\section{Conclusions}

The present study focused on the role of multimodal discourse in Iraqi EFL learners' writing skills. The multimodal discourse theory offers a new perception for the College English teaching. The teaching mode based on the multimodal discourse theory deliveries the realistic situation and the assistant condition for the College English teaching, thus elevating the teaching efficiency greatly. In this kind of class, many modes can't be neglected and arbitrarily shared. The choice of mode must supply to the discourse situation consequently and proportionally. Consequently when the teacher makes the PPTs and chooses the way of multimodal teaching, the use of multimode must be reasonable, depending on the real situation.

Results of t-test confirmed significantly positive role of multimodal discourse in Iraqi EFL learners' writing skills, implemented throughout the course. Multimodal discourse, thanks to recent developments in electronic area, can be implemented in EFL settings where teachers and learners alike can send and receive written products in a short period of time. These contexts, in which there is no face-to-face interaction, can facilitate the process of teaching and learning. Recently, according to Ho (2012), with the employment of multimodal discourse, many writing teachers have employed synchronous or asynchronous peer review to teach their learners. The learners in this research were all at the upper intermediate level of proficiency which limits the generalizability of the result only to this proficiency level. Also, the time period for the investigation is limited to only one term of institutes, about two months which may affect the generalizability or external validity of the result. Also, because of the inability of the researcher to randomly select the participants of the research, the results are limited to the degree of their generalizability as is also clear in the choice of the design of the study an experimental design. This research is defective to paragraph writing specifically to make progress in writing.

\section{References}

1. Allami, H., \& Salmani-Nodoushan, M. A. (2007). A cognitive approach to teaching in EFL writing classes. Iranian Journal of Language Studies (IJLS), 1(1), 65-72.

2. Bereiter, C., \& Scardamalia, M. (1987). The psychology of written composition. Hillsdale. NJ: Erlbaum.

3. Brown, J., \& Hudson, T. (1998). The alternatives in language assessment. TESOL Quarterly, 32, 653 675.

4. Fulcher, G. (2003). Testing second language speaking. London: Pearson Longman.

5. Halliday, M. A. K. (1985). An Introduction to Functional Grammar. London: Edward Arnold.

6. Gu, Y. G. (2007). Discussion about multimedia and multimodal learning. Computer-assisted Foreign Language Teaching, (2), 3-12.

7. Ho, M-C. (2012). the efficacy of electronic peer feedback: from Taiwanese EFL students' perspectives. International Journal of Arts \& Sciences, 5(5), 423-428.

8. Hu. Z. L. (2007). Multimodal in the research of social semiotics. Language Teaching and Research, (1), $1-10$.

9. Harris, K. R., \& Graham, S. (1996). Making the writers process work: Strategies for composition and self-regulation (2nd Ed.). Cambridge: Brookline Books.

10. Knoblauch, C. H. and Lil Brannon. (1984). Rhetorical traditions and the teaching of writing.

11. Kenyon, D. (1992). An investigation of the validity of the demands of tasks on performance assessment: The development and validation of a rating scale. $\mathrm{PhD}$ dissertation, University of Auckland.

12. Kress, G. \& van Leeuwen. (2001). Multimodal Discourse: The Modes and Media of Contemporary Communication. London: A mold.

13. Lee, I. (2007). Assessment for learning: Integrating assessment, teaching and learning in ESL/EFL writing classroom. The Canadian Modern Review. 64, 119-214.

14. Lesley, T., Hanson, C., \& Zukowski/Faust, J. (2005). New interchange/passages placement and evaluation package. Cambridge University Press.

15. LeVine, Philip \& Ron Scollon. (2004). Discourse and Technology: Multimodal Discourse .Washington, DC: Georgetown University Press.

16. Long, Y. F. \& Zhao, P. (2009). Meta-cognitive strategies for EFL listening teaching and interaction of multi-modals.

17. McNamara, T. (2000). Language Testing Oxford: Oxford University Press.

18. Morenoy, R., (2007). Multimodal learning environments.

19. Prof, A., \& Abdulkareem, K. (2020). Internationalization Discourse A Multimodal Analysis of University Websites in Iraqi Kurdistan Region. Journal of Xidian University, 14(4), $203-214$. https://doi.org/10.37896/jxu14.4/028

20. Short, D., Cloud, N., Gomez, E., Hamayan, E., Hudelson, S., \&Ramirez, J. (1997). ESL standards for pre-k-12 students. 
21. Shojaei, A., Fatemi, M., A., (2016). The Effect of E-assessment on Writing Skill of Iranian Upper Intermediate EFL learners... Modern Journal of Language Teaching Methods. Volume 6

22. Wei Q. H. (2009). Multimodal and students' multiliteracies. Computer-assisted Foreign Language Teaching, (3), 28-32.

23. Xin, Z. Y. (2008). New development of discourse: of multi-modals. Social Sciences, (5), 208-211.

24. Zimmerman, B. J., \& Reisemberg, R. (1997). Becoming a self-regulated writer: A social cognitive perspective. Contemporary Educational Psychology, 22, 73-101.

25. Zhang, D. L. (2009). Comprehensive theoretical framework for multimodal discourse. Foreign Languages in China, (1), 24- 30.

26. Zhu, Y. S. (2007). Theoretical basis and research method for multi-modal discourse. Foreign Languages, (5), 82-86.

27. Zhu, Y. S. (2008). Multiliteracy research and its implications for Chinese EFL teaching reform. Foreign] Language Research, (5), 10-14. 